\title{
Analisis Didaktis untuk Meningkatkan Hasil Belajar Calon Guru Fisika Ditinjau dari Gaya Kognitif dan Gaya Belajar
}

\author{
${ }^{1}$ Ahmad Busyairi1, ${ }^{2}$ Ahmad Harjono, ${ }^{3}$ Muhammad Zuhdi \\ ${ }^{1,2,3}$ Prodi Pendidikan Fisika, FKIP, Universitas Mataram, Jln. Majapahit, No.62, Kota \\ Mataram, Nusa Tenggara Barat, 83125. \\ Email Korespondensi: ahmad.busyairi@unram.ac.id
}

\begin{tabular}{|c|c|}
\hline Article Info & bstract \\
\hline Arti & \multirow{2}{*}{$\begin{array}{l}\text { This study aims to analyze the learning outcomes of prospective physics } \\
\text { teachers in terms of cognitive and learning styles. The sample consisted of } 47 \\
\text { prospective physics teachers at the University of Mataram. The instruments } \\
\text { used consisted of the Group Embedded Figures Test (GEFT), the VAK learning } \\
\text { style questionnaire, and the learning outcomes test instrument. The research } \\
\text { data were then categorized and analyzed using descriptive statistics to see a } \\
\text { picture of student learning outcomes in terms of their learning styles and } \\
\text { cognitive styles. Based on the results of data analysis, it can be seen that there } \\
\text { are differences in learning outcomes between students who have a field } \\
\text { independence (FI) cognitive style and students who have a field dependence } \\
\text { (FD) cognitive style. Students who have FI cognitive style tend to get better } \\
\text { scores when compared to FD. When viewed from the learning style, it can be } \\
\text { seen that the number of students who have visual learning styles is } 46.80 \% \text {, } \\
\text { audio is } 8.51 \% \text {, and kinesthetic is } 44.68 \% \text {. Students who have a kinesthetic } \\
\text { learning style tend to get better scores when compared to students who have a } \\
\text { visual and audio learning style. By paying attention to the characteristics and } \\
\text { percentage of students who have FI and FD cognitive styles and students who } \\
\text { have visual, audio, and kinesthetic learning styles, one alternative learning that } \\
\text { can be used to improve student learning outcomes is cooperative or } \\
\text { experimental-based collaborative learning model. }\end{array}$} \\
\hline & \\
\hline Informasi Artikel & \\
\hline & \multirow[b]{2}{*}{$\begin{array}{l}\text { Penelitian ini bertujuan melakukan analisis hasil belajar calon guru fisika } \\
\text { ditinjau dari gaya kognirif dan gaya belajar mereka. Sampel terdiri dari } 47 \\
\text { calon guru fisika di Universitas Mataram. Instrumen yang digunakan terdiri } \\
\text { dari Group Embedded Figures Test (GEFT), angket gaya belajar VAK, dan } \\
\text { instrumen tes hasil belajar. Data hasil penelitian kemudian dikategorikan dan } \\
\text { dianalisis menggunakan statistik deskriptif untuk melihat deskripsi hasil belajar } \\
\text { mahasiswa jika ditinjau dari gaya belajar dan gaya kognitif mereka. } \\
\text { Berdasarkan hasil analisis data terlihat bahwa terdapat perbedaan hasil belajar } \\
\text { antara mahasiswa yang memiliki gaya kognitif field Independence (FI) dengan } \\
\text { mahasiswa yang memiliki gaya kognitif field dependence (FD). Mahasiswa } \\
\text { yang memiliki gaya kognitif FI cenderung mendapatkan skor yang lebih baik } \\
\text { jika dibandingkan dengan FD. Jika ditinjau dari gaya belajar, terlihat bahwa } \\
\text { jumlah mahasiswa yang memiliki gaya belajar visual sebanyak 46,80\%, audio } \\
8,51 \% \text {, dan kinestetik } 44,68 \% \text {. Mahasiswa yang memiliki gaya belajar } \\
\text { kinestetik cenderung mendapatkan skor yang lebih baik jika dibandingkan } \\
\text { dengan mahasiswa yang memiliki gaya belajar visual dan audio. Dengan } \\
\text { memperhatikan karakteristik dan persentase jumlah mahasiswa yang memiliki } \\
\text { gaya kognitif FI dan FD serta mahasiswa yang memiliki gaya belajar visual, } \\
\text { audio, dan kinestetik, maka salah satu alternatif pembelajaran yang dapat } \\
\text { digunakan untuk meningkatkan hasil belajar mahasiswa adalah model } \\
\text { cooperative atau collaborative learning berbasis eksperimen. }\end{array}$} \\
\hline $\begin{array}{l}\text { bela } \\
\text { kog }\end{array}$ & \\
\hline
\end{tabular}


Sitasi: Busyairi, A., Harjono, A., \& Zuhdi, M. (2021 Analisis Didaktis untuk Meningkatkan Hasil Belajar Calon Guru Fisika Ditinjau dari Gaya Kognitif dan Gaya Belajar, Kappa Journal. 5(2), 174-182.

\section{PENDAHULUAN}

Dalam Undang-Undang Nomor 20 Tahun 2003 tentang Sistem Pendidikan Nasional dijelaskan bahwa Pendidikan adalah usaha sadar dan terencana untuk mewujudkan suasana belajar dan proses pembelajaran agar peserta didik secara aktif mengembangkan potensi dirinya. Dari definisi di atas terlihat bahwa suasana belajar dan proses pembelajaran merupakan unsur fundamental dalam setiap penyelenggaraan pendidikan. Tercapai atau tidaknya tujuan pendidikan bergantung pada proses belajar yang dialami oleh peserta didik. Oleh karena itu, faktor utama yang harus dibenahi agar tujuan pendidikan tercapai dengan optimal adalah kualitas proses belajar mengajar di sekolah.

Proses belajar yang terjadi dalam diri setiap individu dapat dipandang sebagai suatu proses pengolahan informasi. Proses ini dimulai dari input berupa informasi yang datang dari lingkungan, diterima oleh pancaindra, kemudian diperoses dan disimpan di dalam memori. Informasi yang tersimpan dalam memori sewaktu-waktu dapat dipanggil dan disusun kembali sesuai kebutuhan guna untuk merespon setiap permasalahan yang dihadapi (Jamaris, 2012).

Dalam proses belajar, panca indra berfungsi sebagai jembatan yang menghubungkan dunia luar (lingkungan) dengan sistem otak manusia. Indra manusialah yang menerima informasi dari lingkungan kemudian dilanjutkan ke otak. Namun yang perlu digaris bawahi adalah orientasi dan tingkat kepekaan indra dalam menerima informasi pada setiap individu berbeda-beda. Perbedaan orientasi inilah yang membuat cara pemerosesan informasi dalam struktur kognitif setiap individu berbeda (Jamaris, 2012). Perbedaan cara belajar ini selanjutnya disebut dengan gaya belajar.

Gaya belajar dapat didefinisikan sebagai cara termudah dan tercepat seseorang dalam belajar (Hamzah, 2010). Sebagian orang mungkin akan lebih mudah dan cepat menyerap materi pelajaran dengan cara mendengar lansung penjelasan dari guru. Hal ini menunjukkan bahwa proses penerimaan informasi pada diri orang tersebut lebih berorientasi pada indra pendengar (audio). (Yunita et al., 2020) Namun ada juga orang yang lebih suka belajar dengan membaca buku teks daripada hanya mendengarkan penjelasan dari guru (visual). Bahkan, ada sebagian orang yang baru bisa memahami materi pelajaran apabila mereka sudah melakukan atau bersentuhan secara langsung dengan benda atau objek yang dipelajarinya (kinestetik) (Wood, 2000; Martimore, 2008; \& Marie, 2010).

Selain gaya belajar, faktor internal yang dapat mempengaruhi hasil belajar siswa adalah perbedaan gaya kognitif (Vergas, et. al., 2017; Lin, et.al., 2018; \& Payung, et.al., 2019). Gaya kognitif merupakan gaya atau karakteristik seseorang dalam menanggapi, memproses, menyimpan, berpikir, dan menggunakan informasi untuk menanggapi suatu tugas atau berbagai jenis situasi lingkungan (Kozhevnikov, 2007). Witkin membagi gaya kognitif kedalam dua bentuk yaitu field independent (FI) dan field dependent (FD) (Onyekuru, 2015). Individu yang memliki gaya kognitif FI cenderung berfikir analitis, detail, kompetitif, individualistik, tidak mudah dipengaruhi oleh faktor ekternal (referensi internal) dan cenderung mengandalkan motivasi intrinsik. Sedangkan seseorang yang memiliki gaya kognitif $F D$ lebih berorientasi kelompok, berfikir global, peka terhadap interaksi sosial, menerima kritik, mudah dipengaruhi oleh faktor eksternal (referensi eksternal), dan cederung mengandalkan motivasi ekstrinsik (Ford \& Chen, 2001; Altun \& Cakan, 2006).

Gaya belajar dan gaya kognitif merupakan faktor internal yang dapat mempengaruhi hasil belajar mahasiswa. Namun sayangnya penelitian terkait gaya belajar dan gaya kognitif 
ini masih kurang diperhatikan di Indonesia. Penelitian pendidikan di Indonesia lebih banyak berfokus melihat bagaimana pengaruh penggunaan metode, model dan media pembelajaran terhadap tercapainya hasil belajar. Padahal menurut paham kognitivisme, metode dan media pembelajaran pada hakikatnya dapat dikatakan hanya sebagai pendukung karena kenyataanya dengan menggunakan metode atau media yang sama akan memiliki dampak yang berbeda pada tiap-tiap siswa bergantung pada faktor internal yang ada pada diri siswa. Argumentasi ini diperkuat dengan bukti empiris terhadap hasil penelitian sebelumnya. Berdasarkan hasil studi pendahuluan terhadap hasil penelitian; Gunawan, et.al (2017), Lou, et.al (2017), Tamba, et.al. (2017), Noviana, (2017), Ismuwardani, et.al., (2019), (Syahidi et al., 2020), Milla, et.al., (2019) Putri, et.al., (2019), dan Usmeldi (2018) memperlihatkan bahwa dengan menggunakan model pembelajaran yang sama dapat menghasilkan efek atau pengaruh yang berbeda bagi peserta didik. Perbedaan ini diduga disebabkan oleh faktor internal pada diri peserta didik. Faktor internal yang dimaksut di sini dapat berbentuk gaya belalajar dan gaya kognitif

Perbedaan gaya belajar dan gaya kognitif ini sangat penting untuk diketahui oleh setiap dosen sebelum mereka mengajar di kelas. Dengan mengetahui dan memahami perbedaan gaya belajar mahasiswa, dosen akan lebih mudah memetakan kebutuhan-kebutuhan yang diperlukan oleh mahasiswa tersebut. Selain itu, dengan mengetahui bagaimana kecenderungan pengaruh gaya belajar dan gaya kognitif terhadap hasil belajar mahasiswa, dosen juga akan mengetahui bagaimana seharusnya mahasiwa belajar dan bagaimana guru atau dosen mengajar (Wood, 2000). Peneliti bertujuan untuk mengetahui profil gaya belajar dan gaya kognitif mahasiswa sera pengaruhnya terhadap hasil belajar mereka.

\section{METODE}

Jenis penelitian ini adalah penelitian deskriptif kuantitatif. Penelitian deskriptif merupakan penelitian untuk memberikan uraian mengenai gejala, hubungan, fenomena, atau fakta yang diteliti tanpa diberikan perlakuan (Setyosari \& Widijoto, 2007). Tujuan utama dari penelitian deskriptif yaitu untuk membuat deskripsi atau gambaran secara sistematis dan akurat mengenai fakta-fakta yang menjadi objek penelitian.

Penelitian ini dilakukan di salah satu Universitas yang ada di kota Maratam, Nusa Tenggara Barat, Indonesia. Sampel terdiri dari 47 Mahasiswa Calon Guru Fisika. Pengambilan sampel menggunakan teknik Simple random sampling. Simple random sampling merupakan teknik pengambilan sampel dengan memberikan kesempatan yang sama bagi setiap elemen (anggota) populasi untuk dipilih menjadi anggota sampel (Sugiyono, 2012).

Terdapat tiga instrument utama yang digunakan dalam penelitian ini, yaitu instrument standar Group Embedded Figures Test (GEFT), angket gaya belajar, dan instrumen tes hasil belajar. GEFT (Group Embedded Figures Test) adalah salah satu bentuk tes standar yang dikembangkan oleh Witkin, et.al., (1971). Pemberian tes ini (GEFT) digunakan untuk mengetahui dan mengklasifikasikan gaya kognitif calon guru fisika ke dalam dua bentuk gaya kognitif yaitu field independent (FI) dan field dependent (FD). Angket gaya belajar digunakan untuk mengetahui dan mengklasifikasikan gaya belajar calon guru fisika menjadi tiga bentuk gaya belajar yaitu Visual, Audiotoril, dan Kinestetik (VAK). Intrumen tes dalam penelitian ini digunakan untuk mengukur hasil belajar mahasiswa pada ranah kognitif. Data hasil penelitian kemudian dikategorikan dan dianalisis menggunakan statistik deskriptif untuk melihat gambaran hasil belajar mahasiswa jika ditinjau dari gaya belajar dan gaya kognitif mereka. 


\section{HASIL DAN PEMBAHASAN}

Persentase jumlah mahasiswa calon guru fisika jika diklasifikasikan berdasarkan gaya kognitif dan gaya belajar dapat dilihat pada grafik di bawah ini.

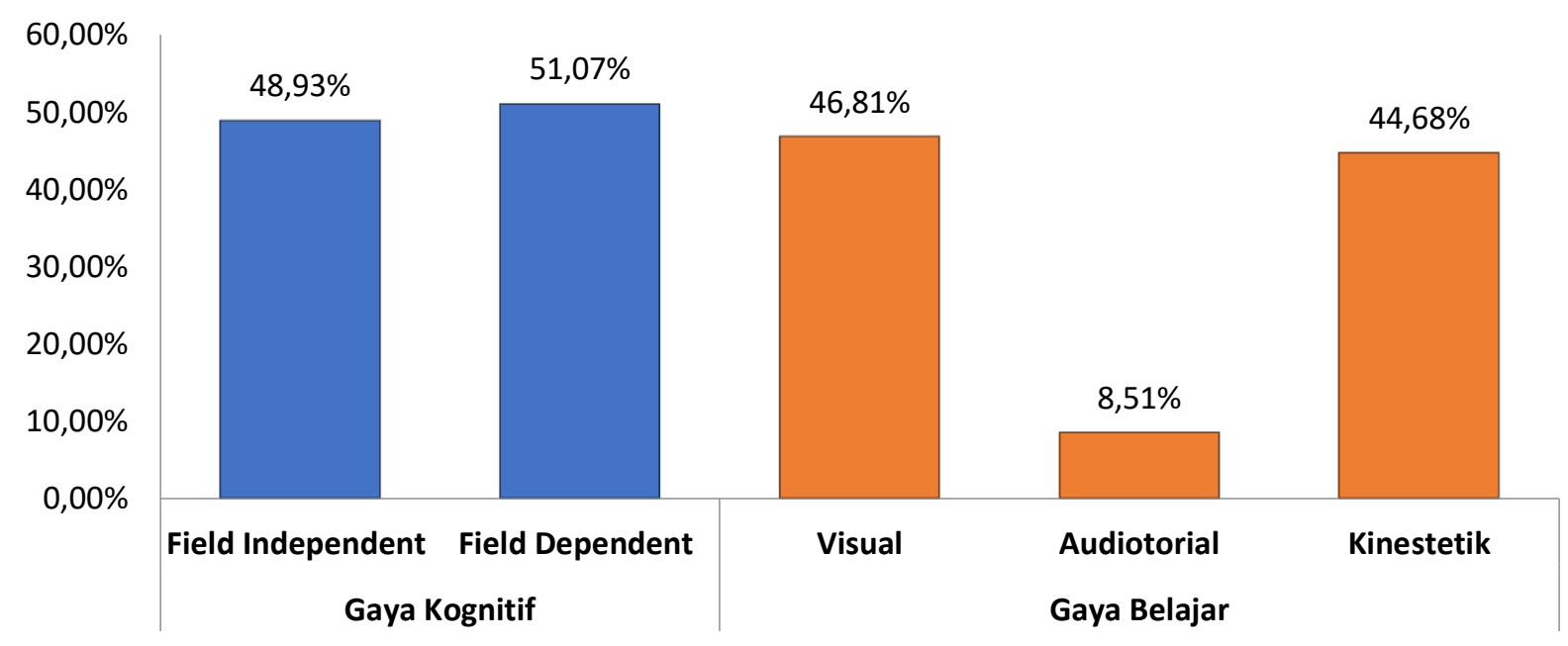

Grafik 1. Persentase jumlah calon guru fisika berdasarkan gaya kognitif dan gaya belajar

Data pada grafik di atas menunjukkan bahwa jumlah calon guru fisika yang memiliki gaya kognitif field Independence (FI) relatif sama dengan jumlah calon guru fisika yang memiliki gaya kognitif field dependence (FD). Selanjutnya, jika dikategorikan berdasarkan gaya belajar mereka terlihat bahwa, terdapat perbedaan persentase yang cukup signifikan antara calon guru fisika yang memiliki gaya belajar audiotorial dengan calon guru yang memiliki gaya belajar visual dan kinestetik. Persentase jumlah mahasiswa yang memiliki gaya belajar audiotorial hanya sebesar $8,51 \%$. Artinya, sebanyak 91,49\% mahasiswa calon guru fisika memiliki gaya belajar visual dan kinestetik. Oleh karena itu, sangat tidak relevan jika dosen dominan menggunakan metode ceramah dalam proses pembelajaran di kelas. Dosen minimal harus mampu memvisualisatikan setiap konsep yang diajarkan untuk memvasilitasi mahasiswa yang memiliki gaya belajar visual. Dosen juga harus mampu mendesain pembelajaran agar mahasiswa dapat berlatih memecahkan masalah dengan menggunakan konsep yang sudah mereka pelajari dengan aktivitas fisik baik secara kelompok atapun individu agar mahasiswa yang memiliki gaya belajar kinestetik turut terfasilitasi dalam setiap kegiatan pembelajaran.

Selanjutnya, untuk keperluan analisis yang lebih mendalam, kita akan menganalisis hubungan antara gaya kognitif (cognitive style) dengan hasil belajar calon guru fisika. Berikut adalah hasil belajar calon guru fisika jika ditinjau dari gaya kognitif (cognitive style) mereka.

Tabel 1. Hasil belajar calon guru fisika ditinjau dari gaya kognitif (Cognitive style)

\begin{tabular}{llc}
\hline Gaya kognitif & N & Rata-rata hasil belajar $(\overline{\boldsymbol{x}})$ \\
\hline Field Independent & 23 & 80,40 \\
\hline Field Dependent & 24 & 74,45 \\
\hline$\overline{\boldsymbol{x}}_{\mathbf{1}}-\overline{\boldsymbol{x}}_{\mathbf{2}}$ & $\mathbf{5 , 9 5}$ \\
\hline
\end{tabular}

Berdasarkan hasil analisis data seperti yang ditunjukkan pada tabel di atas terlihat bahwa, terdapat perbedaan hasil belajar antara mahasiswa yang memiliki gaya kognitif field 
Independence (FI) dengan mahasiswa yang memiliki gaya kognitif filed dependence (FD). Mahasiswa yang memiliki gaya kognitif FI cenderung mendapatkan skor yang lebih tinggi jika dibandingkan dengan mahasiswa yang memiliki gaya kognitif FD. Untuk mengetahui signifikansi perbedaan skor rata-rata hasil belajar ini, selanjutnya dilakukan uji beda (Uji-t). Berdasarkan hasil uji-t pada taraf kepercayaan 95\% $(a=0,05)$ dengan derajat kebebesan $(\mathrm{dk}=$ $n_{1}+n_{2}-2=45$ ) menunjukkan bahwa terdapat perbedaan skor rata-rata hasil belajar yang signifikan antara calon guru fisika yang memiliki gaya kognitif FD dan FI dengan nilai $t_{\text {hitung }}=3,53$ dengan nilai $t_{\text {tabel }}=t_{0,95(45)}=1,68\left(t_{\text {hitung }}>t_{\text {tabel }}\right)$.

Sebagai upaya untuk menemukan faktor yang diindikasikan sebagai penyebab perbedaan hasil belajar antar kedua kelompok gaya kognitif tersebut, selanjut kita akan melihat karakteristik dari individu yang memiliki gaya kognitif FI dan FD. Seseorang yang memiliki gaya kognitif FI adalah seseorang yang memiliki orientasi impersonal, memilih profesi yang bersifat individual, mengutamakan kemampuan berpikir analitis dan sistematis (berfikir konvergen), detail, kompetitif dan mengutamakan motivasi dari dalam diri sendiri (Witkin, dalam (Onyekuru, 2015). Seseorang yang berfikir konvergen cenderung lebih kritis, analitis, dan memiliki kemampuan pemecahan yang lebih baik jika dibandingkan dengan orang yang berfikir divergen (Isaksen, 2007). Pernyataan ini diperkuat oleh hasil penelitian (Ulya, 2015) bahwa siswa yang memiliki gaya kognitif FI memiliki kemampuan pemecahan masalah yang lebih baik dibandingkan dengan siswa yang memiliki gaya kognitif FD. Selain itu, seseorang yang memiliki gaya kognitif FI lebih suka belajar secara individu jika dibandingkan dengan berlajar secara berkelompok (Chou, 2001; Chen, et.al., 2002; Alomyan, 2004; \& Vargas, 2017). Oleh karena itu, seseorang yang memiliki gaya kognitif FI cendrung individualistis, dan bekerja sendiri sendiri meskipun dalam sebuah kelompok.

Berbeda dengan FI, seseorang dengan gaya kognitif Field Dependent (FD) adalah orang yang berpikir global dan menyeluruh (divergen), memiliki orientasi sosial, memilih profesi yang bersifat keterampilan sosial, cenderung mengikuti tujuan dan informasi yang sudah ada, dan cenderung mengutamakan motivasi eksternal (Ford \& Chen, 2001; Altun \& Cakan, 2006). Dengan karakteristik tersebut, seseorang yang memiliki gaya kognitif FD lebih suka belajar secara kolaboratif dan bekerja secara kelompok. Di dalam kelompok, mereka masih bisa membantu siswa lain dan saling memotivasi sehingga dapat meningkatkan hasil belajar (Lee, et., al., 2005). Lebih lanjut Vergas, et. al., (2017) menyatakan bahwa Field Dependent (FD) lebih suka proses penjelajahan yang prosesnya sudah direncanakan, berkerja secara berkelompok dan dipandu oleh agen eksternal.

Dengan melihat perbedaan hasil belajar dan karakteristik dari individu yang memiliki gaya belajar FI dan FD seperti yang dipaparkan di atas, terlihat bahwa metode, pendekatan, strategi, dan atau model pembelajaran yang digunakan selama ini oleh dosen ketika mengajar di kelas belum mampu memfasilitasi kedua gaya belajar mahasiswa. Oleh karena itu, diperlukan alternatif metode dan atau media pembelajaran yang dapat memfasilitasi mahasiswa agar dapat belajar secara kelompok dan belajar secara mandiri. Salah satu alternatif pembelajaran yang dapat digunakan adalah cooperative dan atau collaborative learning berbantukan modul pembelajaran atau media pembelajaran lain yang dapat memfasilitasi mahasiswa untuk dapat belajar secara mandiri. Cooperative dan collaborative learning bertujuan untuk memfasilitasi mahasiswa yang memiliki gaya kognitif FD sesuai dengan karakteristik dari individu yang memiliki gaya kognitif FD seperti yang sudah dipaparkan di atas. Sedangkan penggunaan sumber belajar (modul) atau media pembelajaran yang memungkinkan siswa dapat belajar secara mandiri bertujuan agar mahasiswa yang 
memiliki gaya kognitif FI juga turut terfasilitasi dengan optimal sehingga hasil belajar kedua kelompok sama-sama meningkat seperti yang diharapkan.

Selanjutnya, perbedaan hasil belajar calon guru fisika jika ditinjau dati gaya belajar (learning style) dapat dilihat pada tabel berikut.

Tabel 2. Hasil belajar mahasiswa ditinjau dari gaya belajar (Learning style)

\begin{tabular}{lcc}
\hline Gaya Belajar & N & Rata-rata hasil belajar $(\overline{\boldsymbol{x}})$ \\
\hline Visual & 22 & 77,67 \\
\hline Audio & 4 & 74,25 \\
\hline Kinestetik & 21 & 80,15 \\
\hline
\end{tabular}

Berdasarkan tabel di atas terlihat bahwa terdapat perbedaan hasil belajar antara mahasiswa yang memiliki gaya belajar visual, audio, dan kinestetik. Mahasiswa yang memiliki gaya belajar kinestetik cenderung mendapatkan skor yang lebih tinggi jika dibandingkan dengan mahasiswa yang memiliki gaya belajar visual dan audio. Sedangkan mahasiswa yang memiliki gaya belajar audio memperoleh skor hasil belajar yang paling rendah jika dibandingkan dengan dua gaya belajar lainnya (visual dan kinestetik). Hal ini mengindikasikan bahwa metode, pendekatan, strategi, dan atau model pembelajaran yang digunakan selama ini oleh dosen ketika mengajar di kelas belum mampu memfasilitasi perbedaan gaya belajar mahasiswa. Oleh karena itu, diperlukan alternatif proses pembelajaran dan media pembelajaran yang dapat memfasilitasi ketiga kelompok gaya belajar tersebut.

Sebagai upaya untuk menemukan alternatif pembelajara yang sesuai untuk ketiga gaya belajar, selanjut kita akan melihat karakteristik dari individu yang memiliki gaya belajar visual, audio, dan kinestetik. Gaya belajar visual merupakan gaya belajar yang lebih berorientasi pada indra penglihatan. Ciri-ciri gaya belajar visual adalah mengingat dengan mudah apa yang dilihat, tidak mudah terganggu dengan suara gaduh, lebih suka membaca dari pada dibacakan, lebih suka metode demonstrasi dari pada ceramah, bila menyampaikan gagasan sulit memilih kata, dan menganggap bahwa penampilan sangatlah penting.

Gaya belajar audio merupakan gaya belajar yang lebih berorientasi pada indra penglihatan. Ciri-ciri gaya belajar auditorial yaitu; bicara pada diri sendiri saat belajar, konsentrasi mudah terganggu oleh suara ribut, bersuara agak keras ketika membaca, senang bercerita dan diceritakan, pembicara yang fasih, lebih suka musik dari pada lukisan, bicara dalam irama yang terpola, serta lebih suka gurauan lisan dari pada membaca buku humor.

Gaya belajar kinestetik merupakan gaya belajar yang lebih berorientasi pada indra peraba atau perasa. Ciri-ciri gaya belajar kinestetik adalah lebih suka bekerja dengan tindakan daripada hanya membaca dan mendengarkan, lebih menanggapi perhatian fisik dari pada suara, banyak bergerak dan selalu berorientasi pada aktivitas fisik, menggunakan jari sebagai penunjuk dalam membaca, banyak menggunakan isyarat tubuh, menyukai permainan yang menyibukkan, dan tidak mudah mengingat letak geografis (Wood, 2000).

Jika kita melihat karakteristik dari ketiga gaya belajar di atas, maka pendekatan, metode, strategi, dan atau model pembelajaran yang dapat digunakan agar ketiga kelompok gaya belajar dapat terfasilitasi adalah pendekatan, strategi, metode, dan model pemebelajaran yang dapat memadukan unsur visual, audio, dan kinestetik dalam satu proses pemebelajarannya. Salah satu alternatif pembelajaran yang dapat memadukan ketiga unsur tersebut adalah model cooperative dan atau collaborative learning berbasis eksperimen baik eksperimen secara real ataupun secara vitual (virtual laboratory). 


\section{KESIMPULAN}

Dengan melihat profil jumlah mahasiswa yang memiliki gaya kognitif field dependence (FD) dan gaya kognitif field Independence (FI) serta memperhatikan karakteristik dari kedua kelompok gaya belajar tersebut, maka salah satu alternatif pembelajaran yang dapat digunakan untuk dapat memfasilitasi kedua kelompok gaya belajar tersebut yaitu model cooperative dan atau collaborative learning berbantukan modul pembelajaran. Cooperative dan collaborative learning bertujuan untuk memfasilitasi mahasiswa yang memiliki gaya kognitif FD sedangkan modul pembelajaran digunakan agar mahasiswa yang memiliki gaya kognitif FI juga turut terfasilitasi dengan optimal sehingga hasil belajar kedua kelompok sama-sama meningkat seperti yang diharapkan.

Selain itu, dengan memperhatikan profil dan karakteristik ketiga kelompok gaya belajar mahasiswa seperti yang dipaparkan di atas, salah satu alternatif pembelajaran yang dapat dijadikan alternatif pembelajaran untuk memfasilitasi ketiga kelompok gaya belajar tersebut yaitu model cooperative dan atau collaborative learning berbasis eksperimen baik eksperimen secara real ataupun secara vitual (virtual laboratory) dilengkapi media atau sumber belajar yang dapat memfasilitasi siswa agar dapat belajar secara mandiri seperti misalnya modul (cetak atau elektronik), CD multimedia interaktif (model drill, tutorial, atau simulasi), dan video pembelajaran.

\section{SARAN}

Penelitian ini bertujuan untuk melakukan analisis didaktis terhadap gaya kognitif dan gaya belajar calon guru fisika yang selanjutnya akan dipergunakan sebagai dasar untuk merancang pembelajaran yang sesuai agar mampu meningkatkan hasil belajar mahasiswa. Tujuan akhir dari penelitian ini yaitu menemukan pendekatan, metode, model, atau media pembelajaran yang dapat digunakan sebagai salah satu alternatif pembelajaran yang dianggap dapat memfasilitasi semua bentuk gaya kognitif dan gaya belajar. Pendekatan, metode, model, atau media pembelajaran yang ditawarkan sebagai solusi dalam penelitian ini masih berupa hipotesis yang perlu diuji efektivitasnya. Oleh karena itu, peneliti menyarankan kepada peneliti selanjutnya agar dapat menguji efektifitas dari pendekatan, metode, model, atau media pemebelajaran yang ditawarkan dalam penelitian ini secara empiris melalui serangkaian penelitian ilmiah.

\section{DAFTAR PUSTAKA}

Alomyan, H. (2004). Individual differences: Implications for web-based learning design. International Education Journal, 4(4), 188-196.

Altun, A., \& Cakan, M. (2006). Undergraduate Students' Academic Achievement, Field Dependent/ Independent Cognitive Styles and Attitude toward computers. Educational Technology \& Society, 9(1), 289-297.

Chen, S. Y., \& Macredie, R. D. (2002). Cognitive styles and hypermedia navigation: Development of a learning model. Journal of the American Society for Information Science and Technology, 53(1); 3-15.

Chou, H. W. (2001). Influences of cognitive style and training method on training effectiveness. Computers \& Education, 37 (1); 11-25.

Ford, N. \& Chen, S.Y. (2001). Matching/ mismatching revisited: An empirical study of learning and teaching styles. British Journal of Educational Technology, 32(1): 5-22. 
Gunawan, Sahidu, H., Harjono, A., and Suranti, N.M.Y., (2017). The Effect of Project Based Learning With Virtual Media Assistance on Student's Creativity In Physics. Cakrawala Pendidikan, 36(6), 167-179.

Hamzah, B. U. (2010). Orientasi Baru Dalam Psikologi Siswa yang Memiliki Gaya Belajar. Jakarta: Bumi Aksara

Isaksen, S. G. (2007). An exploratory studi of the relationships between an assessment of problem solving style and creative problem solving. The Korean Journal of Thingking \& Problem Solving, 17 (1), hlm. 5-26.

Ismuwardani, Z., Nuryatin, A., \& Doyin, M., (2019). Implementation of Project Based Learning Model to Increased Creativity and Self-Reliance of Students on Poetry Writing Skills. Journal of Primary Education, 8 (1): 51 - 58

Jamaris, M. (2015). Orientasi Baru dalam Psikologi Pendidikan. Bogor: Ghalia Indonesia.

Kozhevnikov. M. (2007). "Cognitive Styles in the Context of Modern Psychology: Toward an Integrated Framework of Cognitive Style”. Psychological Bulletin. 133 (3): 464-481.

Lee, C.H.M.,Cheng, Y.W., Rai, S., Depickere, A., (2005). What affect student cognitive style in the development of hypermedia learning system. Computers \& Education, 45 (): 1-19

Lin, P. C., Lu, H.K., \& Lin, Y.C., (2018). A Study of Knowledge Dimension and Cognitive Process Pattern of Cognitive Style Differences in STEM Cooperative Learning Environment. International Journal of Information and Education Technology, 8 (10): 720-724.

Lou, S.J., Chou, Y.C., Shih, R.C., Chung, C.C., (2017). A Study of Creativity in CaC2 Steamship-derived STEM Project-based Learning. EURASIA Journal of Mathematics Science and Technology Education, 13(6):2387-2404

Marie, R.P., \& Law, C.C. (2010). Find the Perfect College for You: 82 exceptional Schools That Fit Your Personality and Learning Style: United States of America: SuperCollege, LLC

Martimore, T. (2008). Dyslexia and Learning Style: a Practitioner's Handbook Second Edition. England: Whurr Publishers

Milla, D., Jufri, A.W., Soeprianto, H (2019). The Effectiveness Pf Project-Based Learning For Biology Class In Developing The Science Processing Skills And Creativity Of High School Students. Journal of Primary Education, 8 (1):25-30

Noviana, H. (2017). Pengaruh Model Project Based Learning Terhadap Kemampuan Berpikir Kreatif Matematika Siswa. Jurnal Edumats, 3(2), 110-117.

Onyekuru, B.U., (2015). Field Dependence-Field Independence Cognitive Style, Gender, Career Choice and Academic Achievement of Secondary School Students in Emohua Local Government Area of Rivers State. Journal of Education and Practice, 6 (10): 7686.

Payung, M.S.B., Nuriah, T., \& Sarkadi (2017). Pengaruh Model Pembelajaran dan Gaya Kognitif Terhadap Hasil Belajar Sejarah Siswa di SMAN 28 Kab. Tangerang, Jurnal Pendidikan Sejarah, 6 (1):29-41 
Putri, S.U., Sumiatri, T., \& Larasati, I. (2019). Improving Creative Thinking Skill Through Project-Basedlearning in Science For Primary School. IOP Conf. Series: Journal of Physics: Conf. Series:1-6.

Setyosari, P., \& Widijoto, H., (2007). Metode Penelitian Pendidikan. Malang: Fakultas Ilmu Pendidikan Universitas Mataram.

Sugiyono, (2012), Statistika Untuk Penelitian. Bandung: Alfabeta.

Tamba, P., Motlan, \& Turnip, B.M., (2017). The Effect of Project Based Learning Model for Students' Creative Thinking Skills and Problem Solving. IOSR Journal of Research \& Method in Education, 7 (5): 67-70

Ulya, H., (2015). Hubungan Gaya Kognitif dengan Kemampuan Pemecahan Masalah Matematika Siswa. Jurnal Konseling GUSJIGANG, 1(2): 2460-1187

Usmeldi, U. (2018). The Effect of Project-based Learning and Creativity on the Students' Competence at Vocational High Schools. Advances in Social Science. Education and Humanities Research. 299():14-17.

Vargas, O.L., Ibáñez, J.I., \& Prada, O.W., (2017). Students' Metacognition and Cognitive Style and Their Effect on Cognitive Load and Learning Achievement. Educational Technology \& Society, 20 (3), 145-157.

Wood, G (2000). How to Study: Discovery How Your Personal Learning Style Can Help you Succeed. New York: Learning Express

Syahidi, K., Hizbi, T., Hidayanti, A., Ditinjau, B., Kemampuan, D., \& Kritis, B. (2020). The Effect of PBL Model Based Local Wisdom Towards S tudent's Learning Achievements on Critical Thinking Skills Pengaruh Model PBL Berbasis Kearifan Lokal Terhadap Prestasi. Kasuari : Physics Education Journal ( KPEJ) Universitas Рариа, 3(1), 61-68.

Yunita, N., Zahara, L., \& Syahidi, K. (2020). Pengaruh Model Problem Based Learning (PBL) Melalui Lesson Study Terhadap Kemampuan Berpikir Kritis Siswa. Kappa Journal, 4(2), 233-239. https://doi.org/10.29408/kpj.v4i2.2756 